\title{
Free radicals in synthesis. Clean reagents affording oxidative or reductive termination*
}

\author{
John A. Murphy \\ Department of Pure and Applied Chemistry, University of Strathclyde, \\ 295 Cathedral Street, Glasgow, G1 1XL, UK
}

\begin{abstract}
Neurotoxic organotin reagents currently play a key role in radical chemistry. As a result, this is an important area for development of new clean replacement reactions. The pharmaceutical industry in particular has had to avoid use of radical methodology for the formation of carbon-carbon bonds for this reason. With the current dawn in green chemistry, a host of new clean radical methods is beginning to flourish. Our aim has been to develop new nontoxic methodology for carbon-carbon bond formation by radical chemistry, which would provide either reductive termination (giving a hydrogen atom to the ultimate radical, as happens with tributyltin hydride), or oxidative functionalization, installing a useful polar group at the site of the ultimate radical. Two methods for effecting radical reactions in an environmentally friendly way are presented: (i) The tetrathiafulvalene (TTF)-mediated radicalpolar crossover reaction converts arenediazonium salts to aryl radicals, which have sufficient lifetime to cyclize onto alkenes-the resulting alkyl radicals couple with $\mathrm{TTF}^{+\bullet}$ to afford sulfonium salts which, in turn, undergo solvolysis to alcohols, ethers or amides. The method provides the key step in a synthesis of ( \pm )-aspidospermidine. (ii) Hypophosphite salts and hypophosphorous acid, on the other hand, form $\mathrm{C}-\mathrm{C}$ bonds with reductive termination. These economical reagents afford radicals efficiently, starting from aryl iodides, alkyl bromides, and alkyl iodides, and give very easy separation of products from by-products.
\end{abstract}

\section{INTRODUCTION}

Free-radical chemistry has undergone a magnificent transformation over the last 30 years. In the past, radicals were generally thought to be too reactive to control and so would be unlikely to have major synthetic applications. This view masked the fact that our understanding of radicals was very limited. Reactions that produce pairs of radicals from closed shell molecules can liberate substantial energy, but it is unusual to need to use that type of process for synthetic chemistry (other than for initiation of a radical reaction with very small amounts of initiator). The corollary of the misconception that radicals were too reactive to control, was that they were unselective in their reactions, and hence a view of radical chemistry as dirty chemistry took hold. In truth, whereas the electron deficiency of radicals makes them reactive, cations are much more electron deficient, and so they are in general far more reactive. Of course, their reactivity is substantially tempered in solution by solvation.

The current general view of radicals is that they are useful and selective intermediates; this change has arisen as a result of at least two significant achievements. The first was the determination of a great body of rate constants [1] for key radical reactions. Since radicals are not solvated, the rates at which they react are generally affected very little, if at all, by a change in solvent (unlike charged reactive intermediates). This means that rate constant data are very important in radical chemistry, and so they have been painstakingly recorded in Landolt-Börnstein [1]. Knowing the rate constants for two potentially competing radical reactions permits exquisite predictive control for radical reactions, surpassing that available for ionic reactions. Secondly, the successful application of radical reactions to total syn-

*Pure Appl. Chem. Vol. 72, No. 7, 2000. A special topic issue on green chemistry. 
thesis of complex molecules [2] demonstrated that sufficient knowledge had been amassed to use radical $\mathrm{C}-\mathrm{C}$ bond formation to solve very complex and delicate chemical problems. These two points changed the perception of radical chemistry, and an understanding of its usefulness grew. However, the fact that still prevented a general acceptance of its use, particularly in the preparation of human medicines, was that the principal reagents used to carry out the synthetic radical chain reactions were based on tin, and prime among them was tributyltin hydride (TBTH). The neurotoxicity of organotin compounds is well known and the difficulty in separating organotin by-products from desired reaction products was a major disadvantage [3].

A general awareness of the difficulties posed by tributyltin hydride was coupled with a recognition that reductive radical chemistry removes functionality from molecules by delivering a hydrogen atom to the final radical. The alternative aim of functionalizing the final radical with a useful (nonhydrogen) reactive grouping was adopted by a number of research groups [4]. One of our aims has been to contribute to the development of radical chemistry by presenting new reactions or developing existing ones, so as to by-pass the unacceptable tin reagents, to escape from the "tyranny of tin" as described by Walton and Baguley [5]. With the dominance of the toxic tin reagents, free-radical C-C bond formation is an ideal focus for research on green chemistry. In this article, I present our approach to environmentally friendly free radical reactions with (a) oxidative and (b) reductive termination steps.

\section{OXIDATIVE TERMINATION: THE TETRATHIAFULVALENE-MEDIATED RADICAL-POLAR CROSSOVER REACTION}

Our simple ideas are based on the chemistry of sulfides and sulfonium salts. An easily oxidized sulfide could transfer an electron to an electrophile, and the resulting radical-anion should undergo fragmentation to afford the organic radical $\mathbf{R}^{\cdot}$ (step A). The lifetime of this radical is now crucial; it can, of course, combine with the sulfur radical-cation to afford a sulfonium salt, but provided that this recombination is not too rapid, $\mathrm{R}^{*}$ can undergo reaction such as cyclization, fragmentation, or atom-abstraction affording a new radical $\mathrm{R}^{\prime}$ (step B). The rate of combination of radicals with the radical cation (as in step C) is therefore a central issue. After step C, the radical chemistry is over; the final step (step D) transforms the sulfonium salt product. In the scheme, the transformation shown is a substitution, but other reactions of sulfonium salts could also be used here. The particular attraction of substitution is that it regenerates the sulfide, and so, if the four steps could be achieved in one pot, a catalytic cycle would result, thus making the process even more attractive. Since the final substitution step occurs by a non-radical polar step-it

Radical-Polar Crossover Strategy

Step A

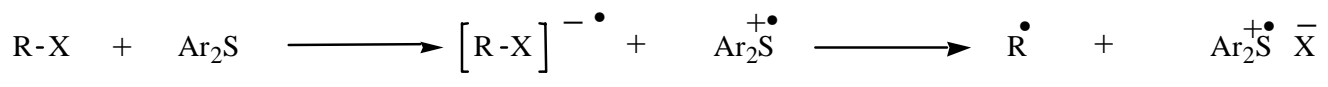

Step B

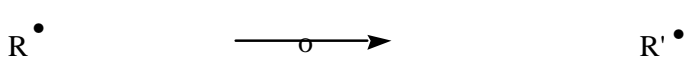

Step C

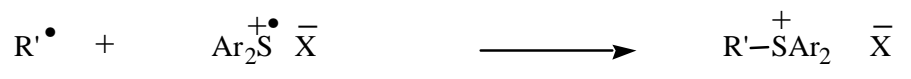

Step D

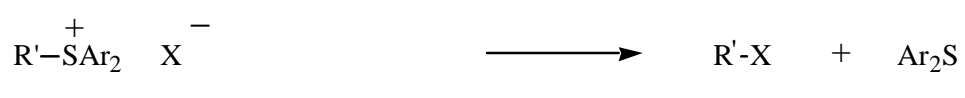

(C) 2000 IUPAC, Pure and Applied Chemistry 72, 1327-1334 

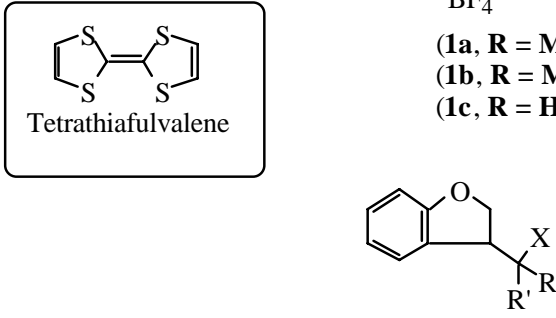

$(\mathbf{4} \mathbf{a}, \mathbf{b} \mathbf{X}=\mathbf{O H})$

$(5 \mathbf{a}, \mathbf{X}=\mathbf{O M e})$

$(6 \mathbf{a}, \mathrm{X}=\mathrm{NHAc})$

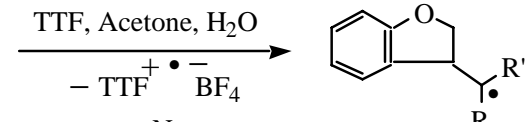

$-\mathrm{N}_{2}$

(2a-c)

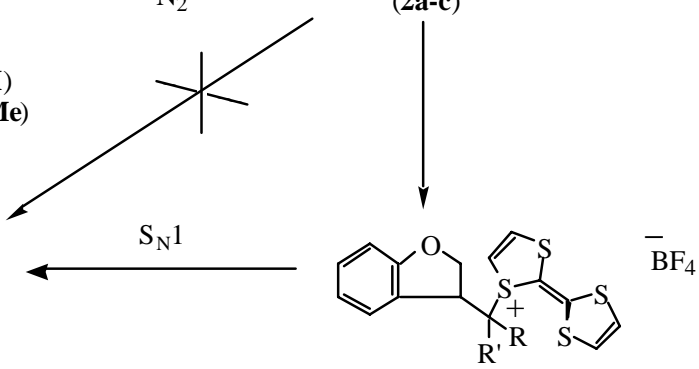

$(3 \mathbf{a}-\mathbf{c})$

could occur by $\mathrm{S}_{\mathrm{N}} 1$ or $\mathrm{S}_{\mathrm{N}} 2$-we termed the overall process a "radical-polar crossover" reaction.

The choice of sulfide for this reaction was not difficult. Tetrathiafulvalene (TTF) is widely used in materials chemistry [6] as an easily oxidized sulfide. This compound is available commercially, but can be prepared conveniently and on large scale using the inexpensive method of Moore and Bryce [7]. Arenediazonium salts were chosen as the reaction partners, since they are excellent electron acceptors and easily prepared. In order to characterize the diazonium salts as fully as possible, we have generally used the isolable tetrafluoroborate salts, but on occasion we have also used the diazonium chlorides in situ, and they provided similar results.

Reaction of the diazonium salt (1a) with TTF at room temperature in undried acetone afforded [8] a good yield of the alcohol (4a). It is important to note that direct reaction between the radical (2a) and water to form the alcohol product is not possible-water is the most inert of common solvents for radical reactions. Further study of the experiment isolated (3a) as an intermediate, which was then transformed under controlled conditions into the alcohol product $(\mathbf{4 a})$. Repeating the experiment with diazonium salt (1b) afforded the corresponding alcohol, but the salt (1c) afforded the sulfonium salt (3c), and solvolysis of this salt has so far proved elusive. Since secondary salts undergo solvolysis, whereas primary salts do not, the solvolysis must be unimolecular. Attempts to force the solvolysis of (3c) with more powerful nucleophiles by $\mathrm{S}_{\mathrm{N}} 2$ reactions, led to destruction of the TTF ring system.

It was also shown [8] that if the salt (1a) were reacted in dry methanol or acetonitrile, analogous reactions occurred affording methyl ether $(\mathbf{5 a})$ and acetamide $(\mathbf{6 a})$, respectively.

The catalytic nature of the TTF was also demonstrated in these reactions. However, TTF is by no means a perfect catalyst and the turnover number is very low. This is likely to be due to attack on the intermediate radical-cation and on the intermediate sulfonium salts (3), and better catalysts are currently being designed. Nevertheless TTF shows that the radical-polar crossover idea is successful and provides a new polar termination for radical reactions. The direct formation of alcohol products is particularly useful.

The above experiments indicate that the coupling of the $\mathrm{TTF}^{\cdot}$ with carbon radicals, under the conditions of the experiment, is not as rapid as we had feared, and that at least this very rapid radical cyclization $(\mathbf{1}) \rightarrow(\mathbf{2})$ is not impeded—no trapping of the aryl radical by $\mathrm{TTF}^{+\bullet}$ was observed. To probe whether a slower cyclization could occur, we reacted the substrate (7). Here, the second cyclization [i.e., the cyclization of $(\mathbf{8})$ ], is substantially slower [9] than the cyclization of the preceding aryl radical, and in reaction with TTF we isolated [10] a mixture of the two alcohols (9) and (10). Since the second cyclization has a rate constant [9] of about $10^{7} \mathrm{~s}^{-1}$, this implies that, at least with TTF under these conditions, only very rapid cyclizations will be successful. The rate of trapping of carbon radicals can be modulated by changing the structure of the radical-cation [11], but investigations in this area are at an early stage.

(C) 2000 IUPAC, Pure and Applied Chemistry 72, 1327-1334 

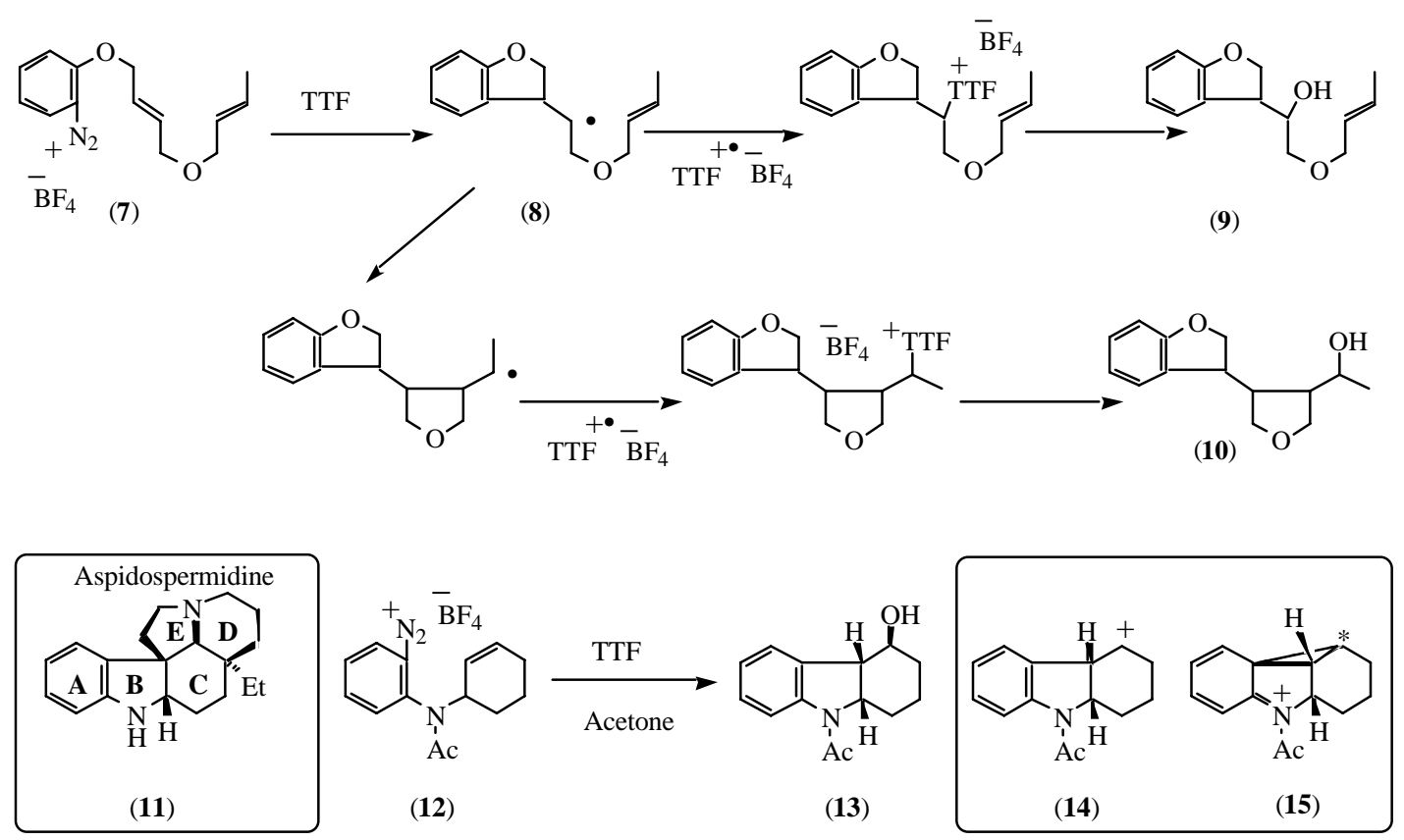

To investigate whether this radical-polar crossover reaction could be used in synthesis of complex molecules, we began our studies on the alkaloid aspidospermidine (11). The crucial model reaction to prepare the $\mathbf{A B C}$ ring system involved making a functionalized tricyclic alcohol (13) using the radicalpolar crossover reaction.

When the diazonium salt (12) was treated [12] with TTF in acetone, the desired tricyclic alcohol was isolated as a single stereoisomer in $65 \%$ yield. The stereoselectivity of the reaction was noted, and also the fact that no cationic rearrangements are observed, although the reaction should proceed via the carbocation (14). This cation ought to be susceptible to rearrangement to more stable carbocations, but the rearrangements are not observed. It is only recently that computational [13] and experimental [14] results have explained this. The intermediate is unlikely to be the free cation (14), but rather, the Wheland intermediate (15). The stereochemistry of this intermediate, which is dictated by the stereochemistry of the starting diazonium salt (12), provides protection from attack on the lower face of the carbon $\mathrm{C}^{*}$. It appears that this neighboring group participation [14] by the aryl ring (or other groups) [14] is, in fact, an absolute requirement for solvolysis.

Having prepared the simple tricycle, we next produced [15] the more complex analogue (17a) as shown. The alcohol group, introduced by the radical-polar crossover reaction, now proved crucial for the completion of the synthesis. Oxidation to the ketone (18) allowed introduction of a two carbon ethylidene side chain by aldol chemistry. Alternative approaches to alcohol (17a) [e.g., by treating salt (16) with iodide ion to form (17b) or its epimer, followed by solvolysis with silver acetate] did not afford the acetate ester of (17a) or (19) in acceptable yield. Hence, the radical-polar crossover reaction provided a unique addition to chemical methodology allowing completion [16] of the synthesis, which demonstrates that the radical-polar crossover reaction can be used for the preparation of complex molecules.

More recently, our efforts have focused on making this reaction even more convenient, by preparing water-soluble TTF [17] (20) and polymer-supported TTF [18] (21). The water-soluble reagent can be easily prepared from TTF, and can be reacted with water-soluble diazonium chlorides, generated in situ. The organic product is isolated by simple extraction, making this an attractive procedure for industrial use. It is noteworthy that no alkyl chloride product is seen-only alcohols are isolated. The polymer-supported reaction is conducted in acetone, and isolation of the product is again very easy. How- 


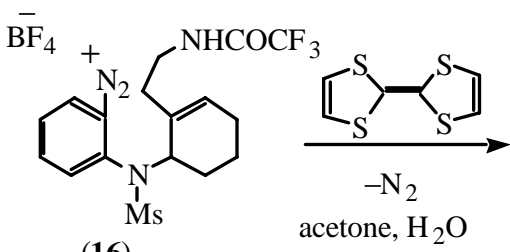

(16)<smiles>[X]C1CCCC2(CCNC(=O)F)N([Y15])c3ccccc3C12CCNC(=O)F</smiles>

(17a), $\mathrm{X}=\mathrm{OH}$

(17b), X = I

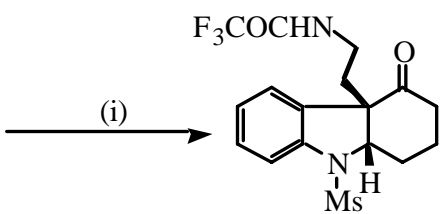

(18)

(ii)

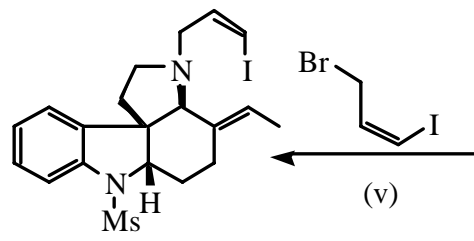

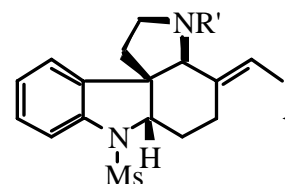

(iv)

(iv) $\square \mathrm{R}^{\prime}=\mathrm{COCF}_{3}$
$\mathrm{R}^{\prime}=\mathrm{H}$

(iii)

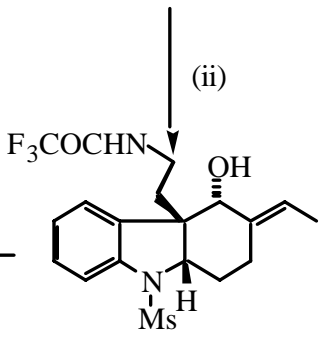

(19)

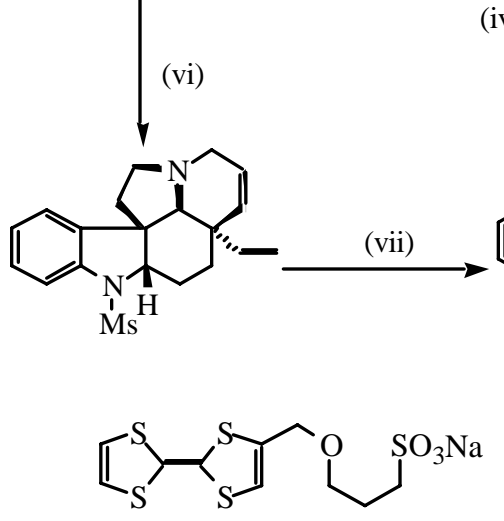

(20)

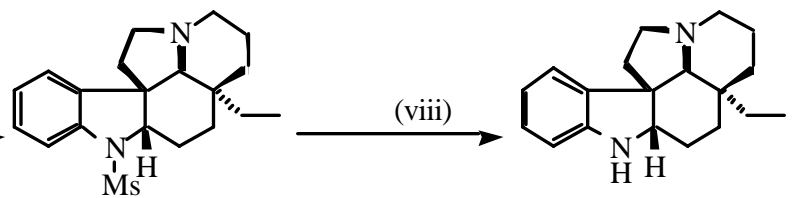

Aspidospermidine ( 11)

Scheme 5 Reagents and conditions: (i) $\mathrm{PCC}, \mathrm{SiO}_{2}, \mathrm{DCM}, 18 \mathrm{~h}, 82 \%$; (ii) (a) TMSCl, Et 3 N, DMF, $80{ }^{\circ} \mathrm{C}, 48 \mathrm{~h}$; (b) $\mathrm{TiCl}_{4}$, paraldehyde, $\mathrm{DCM},-78{ }^{\circ} \mathrm{C} 0.5 \mathrm{~h}$, then r.t. $48 \mathrm{~h}, 51 \%$; (c) $\mathrm{NaBH}_{4}, \mathrm{CeCl}_{3} .7 \mathrm{H}_{2} \mathrm{O}, \mathrm{MeOH}, 0{ }^{\circ} \mathrm{C}, 100 \%$; (iii) DEAD, $\mathrm{PPh}_{2} \mathrm{Me}$, THF, $0{ }^{\circ} \mathrm{C}$ to r.t. $99 \%$; (iv) $\mathrm{NaBH}_{4}$, EtOH, $60{ }^{\circ} \mathrm{C}, 82 \%$; (v) $\mathrm{K}_{2} \mathrm{CO}_{3}$, dry THF, $80 \%$; (vi) $\mathrm{Pd}(\mathrm{OAc})_{2}, \mathrm{Et}_{3} \mathrm{~N}, \mathrm{PPh}_{3}$, dry $\mathrm{CH}_{3} \mathrm{CN}$, reflux, 37\%; (vii) $10 \% \mathrm{Pt} / \mathrm{C}, 40$ psi, EtOH, 5 days, 58\%; (viii) Red-Al, toluene, $100{ }^{\circ} \mathrm{C}, 84 \%$.

ever, if the filtration of the polymer beads at the end of the reaction is conducted under air, then the polymer-bound TTF is present as its radical-cation, and a regeneration step with sodium borohydride is then used to reactivate the polymer for another cycle. We have used samples of this polymer for four consecutive cycles [18] with minimal drop in activity.

\section{REDUCTIVE TERMINATION: HYPOPHOSPHITE SALTS AND HYPOPHOSPHOROUS ACID}

Whereas the radical-polar crossover reaction gives functionalized products (oxidative termination), the development of complementary reagents which afford reductive termination became the next goal. Barton et al. [19,20] and Jang [19,20] had shown that hypophosphorous acid and $N$-ethylpiperidine hypophosphite could be used for the defunctionalization of halides and other groups, but did not use the reagents for the formation of $\mathrm{C}-\mathrm{C}$ bonds. This may have been due to the extensive literature showing facile addition of phosphorus-centered radicals to alkenes. However, in the absence of appropriate rate constants, it could not be stated definitively that the phosphorus reagents would be poor for $\mathrm{C}-\mathrm{C}$ bond

(C) 2000 IUPAC, Pure and Applied Chemistry 72, 1327-1334 


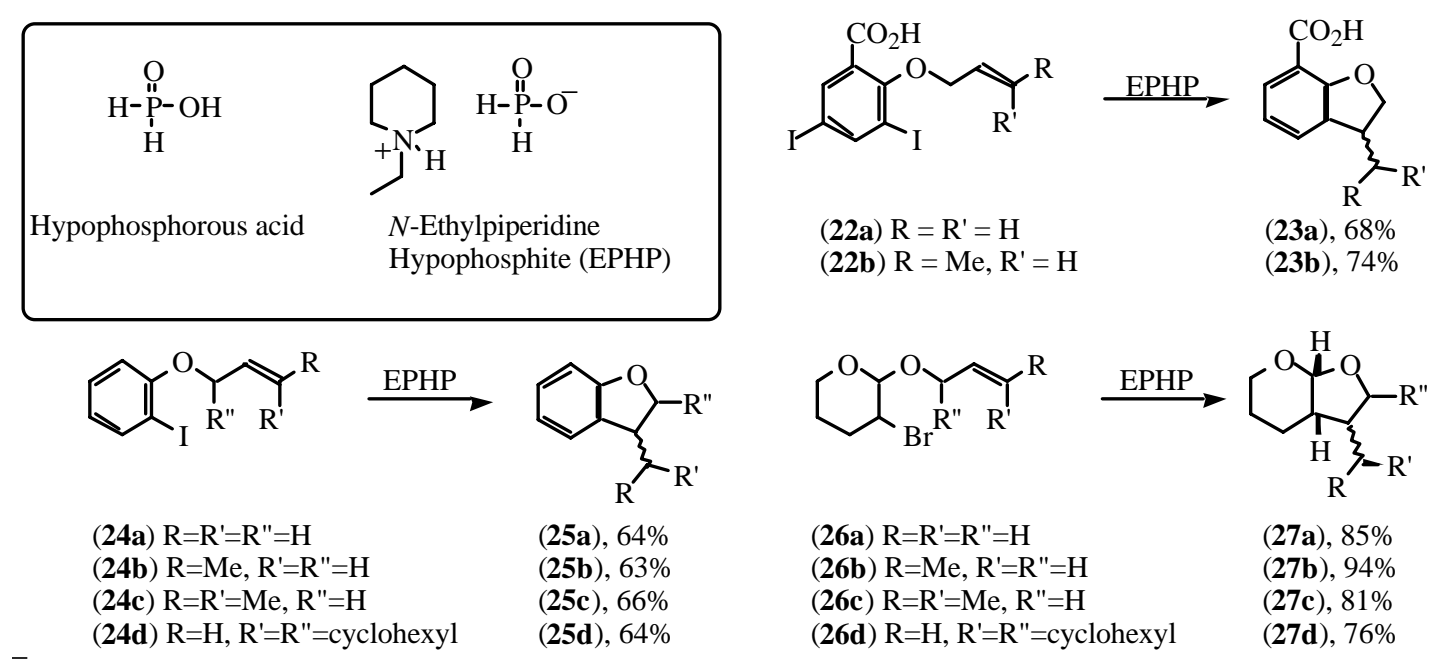

formation. If successful, the low cost of these reagents, and the ease of separation from reaction products by simple extraction would be notable advantages over toxic tin reagents. Our first reactions looked at a number of simple aryl iodides, and alkyl iodides and bromides as substrates [21] for $\mathrm{C}-\mathrm{C}$ bond formation. (The first example of $\mathrm{C}-\mathrm{C}$ bond formation using this type of reaction appears in the patent literature [22]. This has been followed by the studies [23] of Stoodley et al. and, more recently, of Oshima et al. [24]).

How do the phosphorus reagents compare with tributyltin hydride? There are certainly some differences. The hypophosphite reagents are not very reactive towards aryl bromides [19], in contrast to the tin reagent. The greater halide-related selectivity can be put to advantage. Thus, the iodochloride (28) undergoes [25] clean cyclization to (29) (78\%) with the phosphorus reagent, but the corresponding reaction with TBTH affords (29) (35\%) contaminated by substantial quantities of the by-product (30)

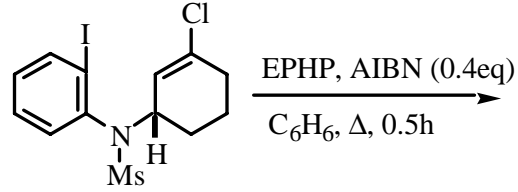

(28)<smiles>[Y13]N1c2ccccc2[C@H]2[C@@H](Cl)CCC[C@H]21</smiles>

(29)<smiles>[Y13]C1c2ccccc2C2(C)CCCCC12</smiles>

(30)

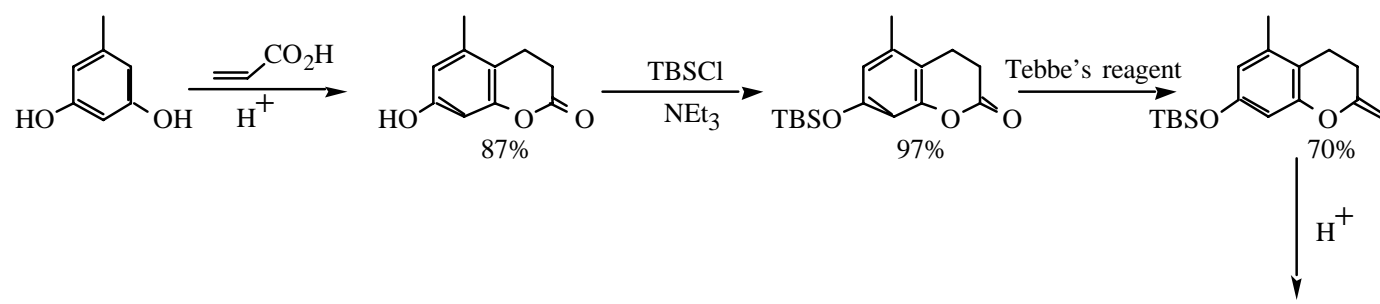<smiles>Cc1cc(O)cc2c1CC1COC3(OCCC3C)OC21</smiles>

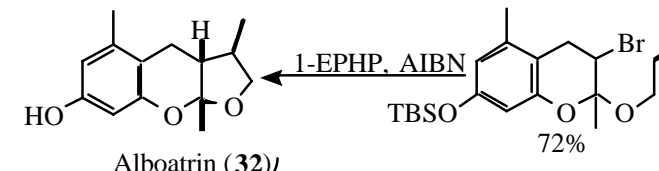
Allyl alcohol NBS

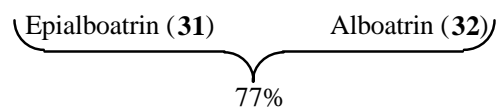


(40\%) presumably arising from reduction of (29). Our studies have concentrated on halide substrates, but complementary to our studies, Fukuyama et al. have elegantly shown [26] the effectiveness of the reagents in indole synthesis starting from thiocarbonyl [19] precursors.

The success of our studies convinced us to explore the use of EPHP in synthesis, and we have recently completed the synthesis [27] of epialboatrin (31) and alboatrin (32). The structure (31) had been assigned [28] to alboatrin, but our studies show that the minor component from the cyclization, (32), has the NMR spectrum of natural alboatrin, while X-ray crystal structure determination shows that the major product has the structure (31).

EPHP appears to be a very clean alternative to TBTH for many reactions. Although its use for C$\mathrm{C}$ bond formation is still in its infancy, its low toxicity and cost are likely to make radical chemistry a very attractive route for preparation of human medicines on a large scale in the near future.

\section{ACKNOWLEDGMENTS}

The work reported in this article results from the dedicated research performed by my team of graduate students and research associates, whose names appear in the references. I thank the EPSRC Clean Synthesis Initiative, SmithKline Beecham Pharmaceuticals, and Merck Ltd. for funding, and the EPSRC

National Mass Spectrometry Centre, Swansea, for high-resolution mass data. Particular thanks are due to Dr. Norman Lewis (SB) and Dr. Martin Pellatt (Merck) for encouragement.

\section{REFERENCES}

1. Landolt-Börnstein, Group II, Vol. 18, Radical Reaction Rates in Solution, H. Fischer (Ed.), Springer, Heidelberg (1997).

2. For a few selected examples, see K. A. Parker and D. Fokas. J. Org. Chem. 59, 3933 (1994); M. D. Bachi and A. Melman. J. Org. Chem. 62, 1896 (1997); T. L. Fevig, R. L. Elliott, D. P. Curran. J. Am. Chem. Soc. 110, 5064 (1988).

3. Separation of tin by-products: P. Renaud, E. Lacôte, L. Quaranta. Tetrahedron Lett. 39, 2123 (1998); D. Crich and S. Sun. J. Org. Chem. 61, 7200 (1996); D. P. Curran and C. T. Chang. J. Org. Chem. 54, 3140 (1989); D. H. R. Barton, W. B. Motherwell, A. Stange. Synthesis 743 (1981); J. M. Berge and S. M. Roberts. Synthesis 471 (1979); J. E. Leibner and J. Jacobus. J. Org. Chem. 44, 449 (1979); E. J. Corey and J. W. Suggs. J. Org. Chem. 40, 2554 (1975); D. P. Curran and S. Hadida. J. Am. Chem. Soc. 118, 2531 (1996); D. L. J. Clive and W. Yang. J. Org. Chem. 60, 2607 (1995); R. Rai and D. B. Collum. Tetrahedron Lett. 35, 6221 (1994); E. Vedejs, S. M. Duncan, A. R. Haight. J. Org. Chem. 58, 3046 (1993); J. Light and R. Breslow. Tetrahedron Lett. 31, 2957 (1990). A. Chemin, H. Deleuze, B. Maillard. Eur. Polym. J. 34, 1395 (1998); J. Junggebauer and W. P. Neumann. Tetrahedron 53, 1301 (1997). For silicon reagents as alternatives to tin reagents, see e.g., C. Chatgilialoglu. Acc. Chem. Res. 25, 188 (1992). S. J. Cole, J. N. Kirwan, B. P. Roberts, C. R. Willis. J. Chem. Soc. Perkin Trans. 1, 103 (1991).

4. For some examples see: B.C. Gilbert, W. Kalz, C.I. Lindsay, P. T. McGrail, A. F. Parsons, D. T. E. Whittaker. Tetrahedron Lett. 40, 6095 (1999); J. Cassayre and S. Z. Zard. Synlett. 501 (1999); J. Boivin, J. Pothier, S. Z. Zard. Tetrahedron Lett. 40, 3701 (1999); C. Ollivier, R. Chuard, P. Renaud. Synlett. 807 (1999); A. J. Clark, D. J. Duncalf, R. P. Filik, D. M. Haddleton, G. H. Thomas, H. Wongtap. Tetrahedron Lett. 40, 3807 (1999); K. I. Booker-Milburn, A. Barker, W. Brailsford, B. Cox, T. E. Mansley. Tetrahedron 54, 15321 (1998); G. A. Molander and C. R. Harris. Chem. Rev. 96, 307 (1996); N. Baldovini, M.-P. Bertrand, A. Carrière, R. Nouguier, J.-M. Plancher. J. Org. Chem. 61, 3205 (1996); G. Binmore, J. C. Walton, L. Cardellini. J. Chem. Soc., Chem. Commun., 27 (1995); T. V. Rajanbabu and W. A. Nugent. J. Am. Chem. Soc. 116, 986

(C) 2000 IUPAC, Pure and Applied Chemistry 72, 1327-1334 
(1994); B. B. Snider and Q. Zhang. J. Org. Chem. 58, 3185 (1993); A. Ali, D. Harrowven, G. Pattenden. Tetrahedron Lett. 33, 2851 (1992); F. Fontana, F. Minisci, E. Vismara. Tetrahedron Lett. 29, 1975 (1988); T. K. Hayes, R. Villani, S. M. Weinreb. J. Am. Chem. Soc. 110, 5533 (1988).

5. J. C. Walton and P. A. Baguley. Angew. Chem., Int. Ed. Engl. 37, 3072 (1998).

6. M. R. Bryce. Aldrichimica Acta 18, 73 (1985); A. E. Underhill. J. Mat. Chem. 2 , 1 (1992); M. R. Bryce. J. Mat. Chem. 15, 1481 (1995); M. B. Nielsen, S. B. Nielsen, J. Becher. Chem. Commun. 475 (1998).

7. A. J. Moore and M. R. Bryce. Synthesis 407 (1997).

8. C. Lampard, J. A. Murphy, N. Lewis. J. Chem. Soc., Chem. Commun. 295 (1993).

9. A. L. J. Beckwith, I. A. Blair, G. Phillipou. J. Am. Chem. Soc. 96, 1613 (1974).

10. R. J. Fletcher, C. Lampard, J. A. Murphy, N. Lewis. J. Chem. Soc., Perkin Trans. 1, 623 (1995).

11. T. Koizumi, N. Bashir, J. A. Murphy. Tetrahedron Lett. 38, 7635 (1997); T. Koizumi, N. Bashir, A. R. Kennedy, J. A. Murphy. J. Chem. Soc., Perkin Trans. 1, 3637 (1999).

12. C. Lampard, J. A. Murphy, F. Rasheed, N. Lewis, M. B. Hursthouse, D. E. Hibbs. Tetrahedron Lett. 35, 8675 (1994).

13. M. F. Jacobsen and J. A. Murphy, unpublished results.

14. N. Bashir and J. A. Murphy. Chem. Commun. 627 (2000).

15. R. Fletcher, M. Kizil, C. Lampard, J. A. Murphy, S. J. Roome. J. Chem. Soc., Perkin Trans. 1, 2341 (1998).

16. O. Callaghan, C. Lampard, A. R. Kennedy, J. A. Murphy. J. Chem. Soc., Perkin Trans. 1, 995 (1999).

17. B. Patro, M. C. Merrett, S. D. Makin, J. A. Murphy, K. E. B. Parkes. Tetrahedron Lett. 41, 421 (2000).

18. B. Patro, M. Merrett, J. A. Murphy, D. C. Sherrington, M. G. J. T. Morrison. Tetrahedron Lett. 40, 7857 (1999).

19. D. H. R. Barton, D. O. Jang, J. Cs. Jaszberenyi. Tetrahedron Lett. 33, 5709 (1992); D. H. R. Barton, D. O. Jang, J. Cs. Jaszberenyi. J. Org. Chem. 58, 6839 (1993).

20. D. O. Jang. Tetrahedron Lett. 37, 5367 (1996). [See also D. O. Jang, D. H. Cho, J. Kim. Synth. Commun. 28, 3559 (1998) for reactions of diphenylphosphine oxide and D. O. Jang, D. H. Cho, D. H. R. Barton. Synlett. 39 (1998) for reactions of di- $n$-butylphosphine oxide].

21. S. R. Graham, J. A. Murphy, D. Coates. Tetrahedron Lett. 40, 2415 (1999). S. R. Graham and J. A. Murphy. EP 98-1159718.

22. J. M. B. Calderon, G. J. Chicharro, R. J. Fiandorn, S. Huss, R. A. Ward. EP 96-500056.

23. R. McCague, R. G. Pritchard, R. J. Stoodley, D. S. Williamson. Chem. Commun. 2691, (1998).

24. H. Yorimitsu, H. Shinokubo, K. Oshima. Chem. Lett. 104 (2000).

25. C. G. Martin, J. A. Murphy, C. R. Smith. Tetrahedron Lett. 41,1833 (2000).

26. H. Tokuyama, T. Yamashita, M. T. Reding, Y. Kaburagi, T. Fukuyama. J. Am. Chem. Soc. 121, 3791, (1999). M. T. Reding and T. Fukuyama. Org. Lett. 1 , 973, (1999).

27. S. R. Graham, J. A. Murphy, A. R. Kennedy. J. Chem. Soc., Perkin Trans. 1, 3071 (1999).

28. A. Ichihara, M. Nonaka, S. Sakamura, R. Sato, A. Tajimi. Chem. Lett. 27 (1988). 